\title{
The increase of popular participation in the master plan review in Osório City, South Brazil
}

\author{
A. Oliveira \\ Osório City Hall, Brazil
}

\begin{abstract}
This paper aims to socialize the increase of popular participation in the master plan review in Osório. Located in the state of Rio Grande do Sul, in Brazil, Osório is 157 years old, $663 \mathrm{Km}^{2}$ and has about 42,000 inhabitants. Its area covers a waterfront strip, coastal plain with 23 lakes and Serra Geral hills, on the side of Riograndense Plateau. By its geographical position, the city is an important touristic road junction and production flow. Such features configure environmental fragility subject to urban expansion in warming in the country. Since 2006, the municipality has had a master plan. Established by law, the text is based on the City Statute (Federal Law) and established parameters for public policies and soils use and occupation with community participation. For this, the plan provides a maximum of 8 years deadline to be reviewed and it is, currently, in this process. Since its implantation, the Law has had two changes (in 2008 and 2013), and a small revision (2011). The proposals came either from the public power or society, entrepreneurs and ordinary people, isolated or in groups, but the centralized public audiences had a weak participation. Nowadays, two chambers act permanently in the master plan: the Technical Organ and Council. The Technical Organ is composed of public server technicians and analyses the weekly demands, which are, afterwards, evaluated by the Council composed of administration members and society members. In the current review, the previous hearings accomplished in the municipality district and places which present peculiarities in relation to urban expansion increased the number of members seven times. There was a deadline for free changes proposals enrollments, and all these suggestions were evaluated by the Technical Organ, Council and Mayor. The result will be presented in a new hearing, whose record will define a more participative Law Project to the Municipal Legislative.

Keywords: master plan, territorial planning, urban management, city democratic management, popular participation.
\end{abstract}




\section{Introduction}

The people participation on the planning policies and city managements is guaranteed in Brazil historically, by the elected members for the executive and legislative positions. Nevertheless, after a period in which the country lived its dictatorial regime, from the $60 \mathrm{~s}$ to the $80 \mathrm{~s}$ in the 20 th century, a great process of discussion about the deep changed needed started in order to grant new administrative heights to the federal, state and municipal fields. Among them, it was the urban change. Lawfully, the subject was formalized in the 1988 Federal Constitution, which established, in their 182 and 183 articles, that the municipalities would become the immediate responsible for the local urban policy, and should guarantee the city to fulfill its social function and promote the welfare of the population.

The centralization of the decisions at a federal level and the imperative technocracy commonly applied to the questions of urban planning along the last decades no longer fit the new democratic opening reality lived by the country. Alongside, the ebullition of international politic episodes in the end of the $80 \mathrm{~s}$ and at the beginning of the $90 \mathrm{~s}$, such as the fall of the Berlin Wall, the Iron Curtain system, including the extinction of the Soviet Union, as well as technological advance and a greater access facility to information demanded a protagonist popular behavior, which did not identified with the simple acceptance of the reactions of the decision taken in superior rankings.

On the other hand, the recent Brazilian democracy needed to rehearse its first steps on a territory where the culture of centrality of power, the political and social paternalism were still reverberating. Especially in the smaller municipalities, far from the big urban centers, it is still present the habit of relying upon traditional surnames as a guarantee of influence and local visibility aiming, financial security. Small towns, which take longer to feel the rural exodus, whose economic activity still depend, mostly on its primary production, tend to present a traditional context of arguments centralization, usually in the political polarization which does not necessarily debates ideologically, but talks about strictly local problems.

In this context, the city of Osório, located on the Southern tip in Brazil, with a little more than a hundred and fifty years old and forty two thousand inhabitants, reflects this dualist reality of the traditional culture built on the first farm families which occupied the region in 18th century, however it needs to meet the democratic demands presented by contemporaneity. The historical bond is challenged by the urban growth, by the warm civil construction organic city, and needs to face the environmental fragility aspects the territory has.

The City Statute, federal law which rules the constitution concerning urban policies, demands an immediate participation of the society on the planning processes and city management. In order to consider that all the territory must be contemplated by the City Master Plan, the City Statute brings a completely new demand for the Brazilian patterns, taking into account that the rural areas get in on this planning - and there, mainly in the rural areas, the conservative and feeder core of traditional culture of the small municipalities live. The labels 
fixation of "Right" and "Left" aggravates the situation. These are attributed to the traditional behavior and to the elaboration of participative policies, respectively - what brings subtly though, a certain pejorative tone to the conservative speech facing the legal demands of collective participation.

In order to meet the statute guidelines, the city hall of Osório elaborated its Municipal Development Master Plan in 2006. As a result of a legal demand, the Plan counted on the popular participation under the coordination of a technical team composed of municipal public servants reinforced by the State Govern specialists, under its regional planning foundation (called "Metroplan"). After nine years of its approval, we realize that the original text opted rather for countersigning the preexisting realities than properly planning with more distant horizons - and maybe this would be the reason why the law has been altered and reviewed for three times. A fourth intervention, a wide review, has been in progress since 2014. Based on previous experiences of weak popular participation in the hearings as well as procedures promoted by public power, the land management team in the city, responsible for master plan ministration, proposed for the current legislation review process, that the debate were decentralized, that the information were minimally leveled on the several districts of the city giving publicity to the Plan and the opportunity of straight participation of the citizens were broadened. Although the normal difficulties of behavior and acceptance change were present, the challenge was to increase the popular backing - which must be the core of a master plan - with the obviousness of the number increase of the community participants along the whole process.

\section{The democratic process in Brazil and the insertion of Osório City in this scenery}

\subsection{The policies of democratic management in Brazil}

When we analyze the recent democracy in Brazil, began thirty years ago, we realize a constant process of widening popular participation spaces in the management of the several public policies. In order to support and oversee government sectors from the city to the "Palácio do Planalto", the legislation demands the action of the organized society in the processes of decision and implementation of programs, projects and actions. The population is present in the representative Councils which count as members either from the Public Administration or from sectors and members from the community. Besides, there is a legal demand that the law projects destined to master plan, health city plan, education, housing, national politics, among so many others, must be presented and discussed in hearings and public consultations, open to the free presence of the citizens. This participative structure, which has been encouraged and increased - and from where the initiative is expected - tries to be at the head of the installed culture in the country during a long period of centralized culture and authoritarian decisions. Montoro [1] states that "the destiny of democracy in Brazil is strictly connected to the decentralization of power and to the 
participation of the society" and that "the Brazilian political process has been excessively centralized and authoritarian." His analysis meets the sense that "since the Brazil-Colony times, the central Power, from top to bottom, an elitist and unfair development model, with the marginalization and the sacrifice of the majority of the people." He goes farther, emphasizing that "with the end of the dictatorship and the difficult construction of the democracy it is necessary to open ways for a decentralization process, strengthening of the local power and the participation of the civil society."

The 1988 Federal Constitution established that it is responsibility of the municipalities the elaboration and management of the urban policies what must take place in line with the national policies which arose from this date. For Santos [2], such determination had as a goal, in addition to transferring for the municipal administration the management of the social policies, "facilitate the participation and the exercise of the citizenship taking into account the proximity of the citizen with the instances of power." This way, the master plan elaboration requirement for municipalities with a twenty thousand inhabitant's population, as well as the concern with the social function the city should fulfill. These discussions covered all the following decade and, while some territorial planning examples in line with the Constitution, one worked to establish regulations to the Magna Carta articles 182 and 183, what would bring a greater clarity and, mainly deadlines for the policies to become practical.

In this context, it is approved the City Statute by the Brazilian Government [3], which in its first article announces that the legislation "establishes public order and social interests rules which regulate the use of urban property for the collective good, citizens safety and welfare, as well as the environmental equilibrium." Focusing on popular participation, the Statute intends to modify what for Montoro was a "clienteles' and excluding social policies pattern" to give place to the direct participation of society, including, mainly, the popular classes, aiming to invert the traditional priorities and the "inequality processes reversion, city development private appropriation and real estate speculation."

\subsection{Osório City}

Osório is a $663,00 \mathrm{Km}^{2}$ city, located in the North Coast in the state of Rio Grande do Sul, South Region in Brazil in a place of a great historical relevance, considering the first protection times and the extreme land colonization of Brazilian territory. In the end of the 17 th century, the coastal strip became known by troopers which came in search of cattle, and it was also the only way to arrive at the spot of the Castilian intrusions where today it is the territory of Uruguay. Historically, in the period from 1921 to 1960, the waterways of the region were explored as a means of transportation and communication which has contributed decisively in the economic, cultural and educational in this city and nearby. From production, essential primary, the big farms in the region formatted an economic profile based on the rural logic from three centuries ago, in which the land owner was the authority and everyone around should obey him - what included, obviously, the great number of black slaves at the time. Economy, politics and religion were subjects exclusive to the ones called, "estancieiros" 
(ranchers) ranch owners as these vast farms were known. Currently, Osório is an important junction of state and federal roads which connect the south of Brazil to the rest of the country, and also the Mercosul neighbors - Argentina and Uruguay. For this reason, the city developed a strong characteristic of regional service provider, and more recently, it focuses its politics and investments in several environmental actions, where we can point out the eolic energy production. According to Geography and Statistics Brazilian Institute (Instituto Brasileiro de Geografia e Estatística - IBGE), data its population is a little more than 42.000 inhabitants and about $90 \%$ of them live in the urban zone in the city, above the national average wish is about $80 \%$.

In accordance to the Federal Law, the Development Master Plan in Osório, instituted by Number 3.902/2006 Law, it is a basic instrument of the city urban expansion and development policies to guarantee the accomplishment of public hearings and debates with the population and representative entities (as determined by the article 40 from the City Statute). Since it came into effect, as it was already explicated, the master plan went through two punctual changes in 2008 and 2013, as well as a superficial review in 2012. Nowadays, it is in final phase the ample process of review, initiated in April, 2014.

\section{The challenge of the participative planning and the local government initiative to democratize the city management}

To people, it was always linked the group organization profile, the canalization of energies en bloc for a determined end. According to Mumford [4], "the main function of the city is to convert the power into form, the energy into culture, the unanimated matter into live symbols of art, the biological reproduction into social creativity." However, he ponders that "new institutional dispositions" are necessary where the city can accomplish positive functions proposed. For the administrative level changes, he states that there must be "dispositions of such a big audacity as those, in the first times, changed the overgrown village and its fortress in the centered and highly organized city."

It is laid that the main goals of the current urban public policies aim the inclusion of the population opinion since the very first movements of planning until the evaluation of the consequent results of guidelines applied in the practice. In so far as this country crawls in democratic advances, on trying to establish a disconnection to the technocrat centralized machine from past governs which shirked the citizens of any opportunity to express their daily observations, the great behavior change challenge: from passivity to protagonism. What was restricted to specialized technicians and decisions which were taken in the government chambers, now it is open for public discussion and spread on media.

It is not surprise, therefore, that coming from this outline, the cities present a great difficulty to promote the participative democratic management, especially those of small size with rural and administrative political historic connected to the government traditional forces. Meanwhile, we add the historical moment of political polarization lived in the last years with the arrival of a federal 
government declared to be left viewed who undertook the inclusion discourse and popular participation and was identified with the social causes. It ended up labeling the initiatives in the sense of democratic management - despite of either the 1988 Constitution or the City Statute are previous to this period. It is tangible that in the great urban centers this bond has an easier dilution, and in the small cities the noise remains longer. Thus, it is clear that the awareness by the community participation in the territorial management must not be an isolated act of one sole law review, rather a constant practice, increasingly innovative aiming the lack of participation passivity break.

In Osório, due to its historical characteristics, it could not be different. The activities previously accomplished which resulted in the current soil and usage occupation law had a decrease in the popular binding. Even today it is common to observe the presence of no more than ten people in a two hundred places auditory to discuss delimiter themes about public policies of the city, such as urban mobility, basic sanitation, and housing among others.

And it is not only in relation to collective participation that we see the obstacles. The local governments administrative structure, where Osório is included, also presents characteristics solidified in time, including from behavior character, which must be reviewed. The constant conflicts between technical views and political decisions, do not contribute for the discourse unity in the sense of promoting the democratic management in the city - when what should prevail, no doubt, is the decision taken as a balanced equation result between technical information and political administrative wisdom. And, although, all the efforts targeting the decisions sharing, Nygaard [5] warns us that it is in the exclusively technical scope that we can define the use and the occupation of space in the city "with the illusion that a wide, detailed and severe control, would improve the urban life conditions", resulting on a set of rules destined to civil construction we know as "urbanity system".

On the other hand, the common practice seen mainly in small cities, the fact that the nominee uses the empiricism to deliberate on the public policies, usually with an immediate idea, it becomes useful the available technical apparatus and can seriously compromise relevant aspects from a necessary medium or long term planning. Thus, even before the motivation pro popular manifestation, it is the Public Management itself, which needs to do their homework and determine the values of the technical and political parameters which are always involved on social matters. This turbulent relationship between technical and politics, especially when it creates the concern of a technocrat regime, in Costa's urban view [6], and from his private experience when projected Brasilia must be seen as a stimulus to leave the comfort zone. He states that it is "puerile the concern of a technocracy; it is not about the monster, which caused so much insomnia in illustrious heads, but from a perfectly domesticated animal (...)", for we understand that, in Brazil, there is a lot to do - and, according to him, a lot to "undo". In his analysis, it would be an over-zealous to give up on the knowledge acquired by the technique based on the simple fear that it could restrict he political action, what in his opinion, is made " more or less by ear, empirically". And concludes wishing that the technical knowledge initiative "comes and 
spreads, awakening with its roughness and vibration this way disenchanted and lazy we have, because the most part - despite of the thoughtful air it has - does not think about anything."

It is a determining factor for a good urban govern to process and land manage the structure of the local government, for he is responsible for the management of the city. Along with its technical body, its administrative organization, including agencies and departments which compose it, one disposes of a greater clarity to define the roles of each area, identifying the human and financial resources available, to promote the articulation needed with federal and state spheres as well as mobilizing the population to participate of the debates. This is the thought present in Acioly and Davidson [7], and it helps us to understand the relevance of the municipal public power role as the first promoter of the democratic management in the city.

So, considering the popular opinion presence requirement as well as the necessary partnership between the technical area of an Administration and its political managers, one can propose that the society collective mobilization be a fundamental piece in the participative system gear of the city, or that it works like a cartilage so that the technique and the politics can, frictionless, act together in a harmonic way. What it is proposed, this way, is a strengthening of the governmental action from the popular participation, and not the opposite. When they realize that it is the population who is demanding for public policies, participating in the advisory cameras and executing its citizenship when supervising the governmental action, the local management has to react and offer, in a legal, technic and political way, the structure to do it facing the challenge.

\subsection{The territorial management democratization search by the public administration of the city}

The city statute establishes that master plans must be reviewed in a maximum period of ten years. The city law, when determining the 8 years' deadline in Osório, that meanwhile diminishes the pointers' observation horizon, forces the local government to dispose of a mobilizing structure to manage the system, so that it has to be able to identify the need to accomplish a new review. After three changes in the master plan had been accomplished since 2006, verified the demands for improvements and corrections originated either by public administration or informally by social sectors, the Management Municipal City Hall team asked for authorization to initiate a master plan wide review - a work which is in progress. Nevertheless, facing the unfavorable historic of low popular assiduity to the previous proposed discussions, the team established a new layout for the participative process, focusing on the democratization of information. The system used in the past, with centralized hearings in the city headquarters approaching all the themes altogether was not very useful. According to Vainer [8], "in this fight for the democratic city, the information occupies a central place" and it will only be a citizen participation in an effective way where information is produced, systematized and spread in a democratic way. He highlights that "without information it is almost always a farce", what gives 
value to the efforts to generate, register and make it accessible the data about the city. This way, public audiences were accomplished, in the very beginning of the process in all the districts of the city and also important places due to its urban expansion characteristics. The theme and the opening to the participation were taken where there would have never been any before, where people had never heard about a directive plan. The city, along its territory, presents specific geographical peculiarities in each region, since the seafront, going through a vast area, the set of interconnected lakes, the Serra Geral slopes, the plateau on the mountains, where each natural scenery consists of different realities of space occupation and urban development profile. Here comes the need of the local government to establish this connection with the several communities, and making use of an accessible language, presenting the potential offered to the common citizen to be a protagonist of the planning of its city. And having the capacity to make yourself understood in the complicated graphic and numeric description of an urban system and to the possible morphologic changes which it can give to the city, for instance, it is also something Nygaard worries about when he states that "well elaborated presentations in public seminars to be organized especially for this end on different neighborhoods in the city" are necessary. And he goes on, when he proposes that debates must be accomplished, propositions allowed and decisions taken by the population from a "clear explanation (...), including with simulations and examples visualizations in relation to the interference of the urban system in life and configuration of the district (...)".

From the decentralized hearings, the population had, at their disposition, a determined space of time to refer their demands. It was intention of the coordination team that the master plan alteration proposals were elaborated after the presentations in the districts, what would allow the requests to be originated into the possible themes and really related to the plan. In previous opportunities, it was verified the presence of matters out of the discussion axes approached by legislation, what was possible to avoid in the current process. Added to the notes selected by the municipal territory management section along with the daily interaction with the theme, there were almost one hundred change proposals to the current law submitted to analysis.

As determined in the Master Plan articles 171 to 176, there are two instances which evaluate and opine about the territorial management in the city: the Technical Organ and the Council. Composed of municipal public server's technics, the Technical Organ is responsible for the first stage in the analysis process of a demanded question which exactly gives opinions about the technical viability of the proposal. The group is composed of five members: an architect and urbanist, civil engineering, forest engineering, agriculture technician and lawyer. In order to expedite the method of the review, the meetings, which were monthly before, are weekly now, avoiding the accumulation of requests and giving a previous unthinking rhythm to the territorial management. As a consequence, the Directive Plan Council was stimulated to greater participation. As a second evaluation level, the Council is composed of representatives of Public Administration (Environment, Civil Construction and Economic 
Development) and representative sectors from society, such as the Engineering Regional Councils and Real Estate Agents, the Business Center of the city, the Order of Attorneys of Brazil and the Development Municipal Council, for instance. This team must guide the City Mayor about the decisions approval based on the technical aspects, native from the first analysis, and social, from the several group's participants opinions. In these two distinct moments - the technical analysis and the social evaluation -the adjustment on the presented review proposals was possible. Filtering the themes with real viability to be concretized, pooled the propositions which verse about the same guidelines or the similar features and qualified the ideas from the popular requests, the demands were formatted in 69 points to be incorporated to the master plan, under the mayor's and the population's opinion in a new public hearing to present the results.

Among all the raised questions, we can highlight: a) the urban perimeter adequacy of the city, whose proposal is to reduce its coverage area, taking into account the urban expansion expectations have not come true since 2006, the law approval year, that aimed a bigger equilibrium in the use and occupation of the soil in the intensive areas of the city; b) adoption of the edification up righting criteria restricted to the main several axes identified in the Municipal Plan of Urban Mobility, keeping the densities and the residential and commercial areas scales; and c) consolidation of the economic development in line with the environment preservation in the creation of the called "employment generation areas" and linking the directive of soil usage and occupation to the environmental protection areas with urban characteristics.

Nevertheless, although such measurements are still proposed to be submitted to the legislative power, the greater verified was, no doubt, the social mobilization and the increase of direct popular participation on the alteration formulation. While in the previous processes, featured by centralized audiences, the registered presences hardly overcame twenty people, only adding the records of the accomplished meetings in this review edition, when decentralized audiences were made, and final presentation audience, without counting the indirect numbers referring to the entities and represented groups, we have a universe next to four hundred participants - which stands for almost $1 \%$ of the city population and an increment of about seven times in the direct participation quantitative when compared to the previous period. For Mumford, "the final mission of the city is to encourage the conscious participation of men in the cosmic process as well as in the historical one" and the engagement of people in the decision process is a valued part of this understanding. According to him, the city, by means of the implied emotions, of the efficient communication, the correct application of technology and the highly dramatic representation which causes, promotes the enlargement of all the dimensions of life - what, historically, have been its function "and remains as the main reason why the city keeps existing". 


\section{Final considerations}

The headed actions by the Land Management Team, along with the Technical Organ and the Master Plan Council checked to the Law Review process a more considerably participative approach when compared to the experimented practices since then. The debate opening as well as the hearings decentralization approximated the population to the Master Plan and gave the community the territorial and urban policies protagonist sense, putting aside the feeling of being supportive. The movement of the local government of meeting the communities in their quotidian places contributed in this process. The hearings in the districts and places were accomplished where they usually held their own meetings community rooms, parish halls and children schools - what contributed to create a familiar environment favorable to the debate as well as spontaneous participation.

This favorable scenery, including the difference access channels availability to the individual and collective participation resulted on a considerable numerical increase of adaptations debaters and applicants' citizens on the local policies of land management. This has been searched since the beginning of the whole process. Therefore, the Law Review project sent to the City Council has a participative role, with the society greater support. The executive and legislative powers, along with the technical area, acted as work facilitators and organizers, for the outcome is, in fact, by right, a popular action work.

However, the challenge, from the new reached level is to solidify this process as a pattern behavior for the urban policies in the city. It is established, though, the initial system for the city democratic management as determined by federal law, in order to keep open the dialogue channels for the available pointers permanent monitoring and for creating. The demand generation procedures from the City Hall general convention, the technical body weekly analysis as well as the Master Plan Council are systematic embryo of the perennial participative management, with the final goal to guarantee the constant presence in the territorial management to the population.

\section{References}

[1] Montoro, A. F. in Fundação Prefeito Faria Lima - Cepam. O município no século XXI: cenários e perspectivas. 400p. 1999.

[2] Santos, M. R. M. in Junior, O. A. S. \& Montandon, D. T. Os planos diretores municipais pós-Estatuto da Cidade: balanço crítico e perspectivas. 295p. 2011.

[3] Brasil. Lei Federal no 10.257/2001. Estatuto da Cidade.

[4] Mumford, L. The City in History - its origins, its transformations and its prospects. $4^{\mathrm{a}}$ edição. 741 p. 1998.

[5] Nygaard, P. D. Espaço da cidade, segurança urbana e participação popular. $1^{a}$ edição. 192p. 2010. 
[6] Costa, L. in Costa, M. E. Com a palavra, Lúcio Costa.167p. 2001.

[7] Acioly, C. \& Davidson, F. Density in Urban Development. 2a edição. 92p. 1998.

[8] Vainer, C. in Erba, D. A. et al. Cadastro multifinalitário como instrumento de política fiscal e urbana. 144p. 2005. 